\title{
AVALIAÇÃO DE RISCO SOBRE A PERDA DE DUCTILIDADE A QUENTE DE BARRAS DE AÇO CA-50*
}

\author{
Alex Maia do Nascimento ${ }^{1}$ \\ Rodrigo Alves Ramos ${ }^{2}$ \\ Francisco Diego Araruna da Silva ${ }^{3}$ \\ Helilton Morais Rego Lima Filho ${ }^{4}$ \\ Claudio Henrique Macedo Alves Filho ${ }^{5}$
}

\section{Resumo}

A capacidade de um determinado aço suportar as deformações ocorridas durante laminação sem fraturas ou trincas severas é denominada de ductilidade a quente, que é função de diversos parâmetros de processo dentre os quais: qualidade do tarugo, tipo de corte, ciclo térmico, temperatura de processo, layout do laminador, calibração, taxa de deformação e composição química. Diversos trabalhos abordam a ductilidade a quente enfatizando a influência isolada de uma variável como critério de qualidade como as conhecidas relações $\mathrm{Mn} / \mathrm{S}$ e Ni/Cu através da determinação de valores mínimos. A globalização tem sido responsável pela crescente competitividade entre as siderúrgicas que, para se manterem competitivas no mercado, têm que buscar inovações, quebras de paradigmas, estratégias ousadas e assumir riscos. No presente trabalho realizou-se uma avaliação de risco com base no princípio ALARP (As Low As Reasonable Practical) através da análise conjunta das principais variáveis de processo responsáveis pela perda de ductilidade a quente de um aço utilizado para produção de barras de aço CA-50, objetivando-se uma solução otimizada de menor custo garantindo a competitividade e sustentabilidade da cadeia produtiva.

Palavras-chave: Ductilidade a quente; Barras de aço CA-50; Avaliação de risco.

\section{Abstract}

\section{RISK ASSESSMENT ON THE HOT SHORTNESS OF CA-50 REBARS}

The ability of a particular steel withstand the deformations occurring during hot rolling without fractures or severe cracks is called hot ductility, which is a function of several process parameters among which: billet quality, cut type, thermal cycle, process temperature, roughing mill strand, pass design, strain rate, and chemical composition. Several works address the hot ductility emphasizing the isolated influence of a particular variable as a quality criterion as the known $\mathrm{Mn} / \mathrm{S}$ and $\mathrm{Ni} / \mathrm{Cu}$ ratios by determining minimum. Globalization has been responsible for increasing competition among steelmakers that, to remain competitive in the market, have to seek innovations, paradigms breaks, bold strategies and take risks. In this work we carried out a risk assessment based on the ALARP principle (As Low As Reasonable Practical) through the joint analysis of key process variables responsible by hot shortness of steel used for the production of rebars CA- 50, aiming to an optimized solution for lower cost, ensuring the competitiveness and sustainability of the business.

Keywords: Hot shortness; CA-50 Rebars; Risk assessment.

\footnotetext{
Consultor Técnico, Doutor em Materiais e Processos de Fabricação, P\&D, Gerdau Aços Brasil

Assessor Técnico, Bacharel em Metalurgia, Aciaria, Gerdau Aços Brasil

Assessor Técnico, Mestre em Metalurgia, Aciaria, Gerdau Aços Brasil

Assessor Técnico, Bacharel em Metalurgia, Aciaria, Gerdau Aços Brasil

Consultor Técnico Sênior, Mestre em Engenharia Mecânica, Laminação, Gerdau Aços Brasil.
} 


\section{INTRODUÇÃO}

As empresas possuem recursos econômicos limitados e para que as decisões relativas a investimentos na redução de risco sejam tomadas de forma eficaz, eficiente e sustentável, é necessário criar critérios de modo a delimitar fronteiras e a definir níveis admissíveis de risco [1].

John Harvey citou "O negócio em si trata-se de aceitar riscos. Organizações que não aceitam riscos desaparecem. Organizações que aceitam riscos inaceitáveis claramente também desaparecem" [2].

O princípio ALARP (As Low As Reasonable Practical) consiste em definir dois níveis de risco: o primeiro consiste num nível de risco absoluto "não admissível" - que não pode ser ultrapassado independente do custo das medidas, o outro representa o nível abaixo do qual o risco é considerado insignificante - não necessita de medidas mitigadoras para além das já existentes. A região entre esses dois níveis é denominada de zona ALARP, na qual o risco apenas é tolerado enquanto o prejuízo causado for menor que o custo da implantação de medidas mitigadoras [3].

A Figura 1 apresenta as três zonas de aceitabilidade do risco, segundo o princípio ALARP.

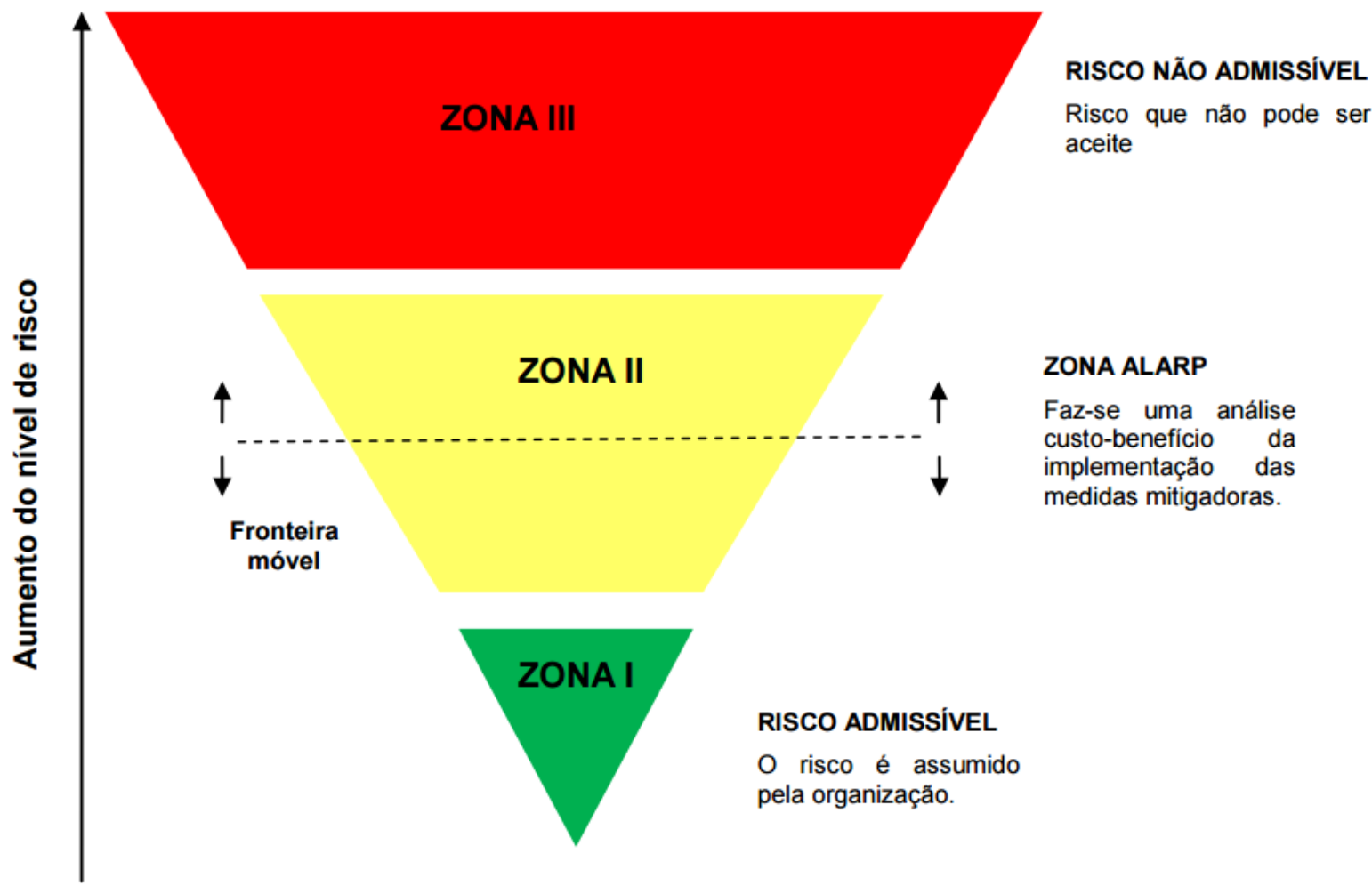

Figura 1 - Triângulo ALARP de tolerância de risco [adaptado de 4].

A zona ALARP remete a necessidade de uma análise custo-benefício. No presente trabalho, essa análise será realizada na avaliação do risco relativo à perda de ductilidade a quente versus os investimentos necessários para implantação de eventuais ações mitigadoras.

Diversos trabalhos abordam a ductilidade a quente enfatizando a influência isolada de uma variável como critério de qualidade devido à complexidade de uma análise empírica correlacionando as "n" variáveis de processo. 
O presente trabalho visa apresentar uma solução otimizada de menor custo do aço para barras de aço CA-50 via mitigação do risco da perda de ductilidade a quente através de uma análise holística das principais variáveis de processo que de fato influenciam.

\section{MATERIAIS E MÉTODOS}

Foi realizado um review sobre a influência das principais variáveis de processo relacionadas à ductilidade a quente de aços ao carbono correlacionando-as com a realidade do processo da planta siderúrgica:

- Qualidade da solidificação do tarugo,

- Tipo de corte do tarugo,

- Ciclo térmico,

- Temperatura de processo de laminação,

- Tipo do trem de desbaste,

- Calibração,

- Taxa de deformação,

- Composição química.

Após a correlação entre literatura e processo real, realizou-se uma análise de risco com base no princípio ALARP objetivando a solução otimizada de menor custo (avaliação de custo-benefício) visando maior competividade e sustentabilidade do negócio.

\section{RESULTADOS E DISCUSSÃO}

A Figura 2 apresenta o desenho esquemático de uma região de baixa ductilidade a quente (em vermelho) que é compreendida entre uma faixa de Temperatura T1 e T2, na qual, o aço em questão apresenta uma perda de ductilidade, acarretando no aparecimento de fissuras/trincas (R1 - representa a ductilidade limite). A faixa de Temperatura é dependente de diversas variáveis de processo, portanto não é constante.

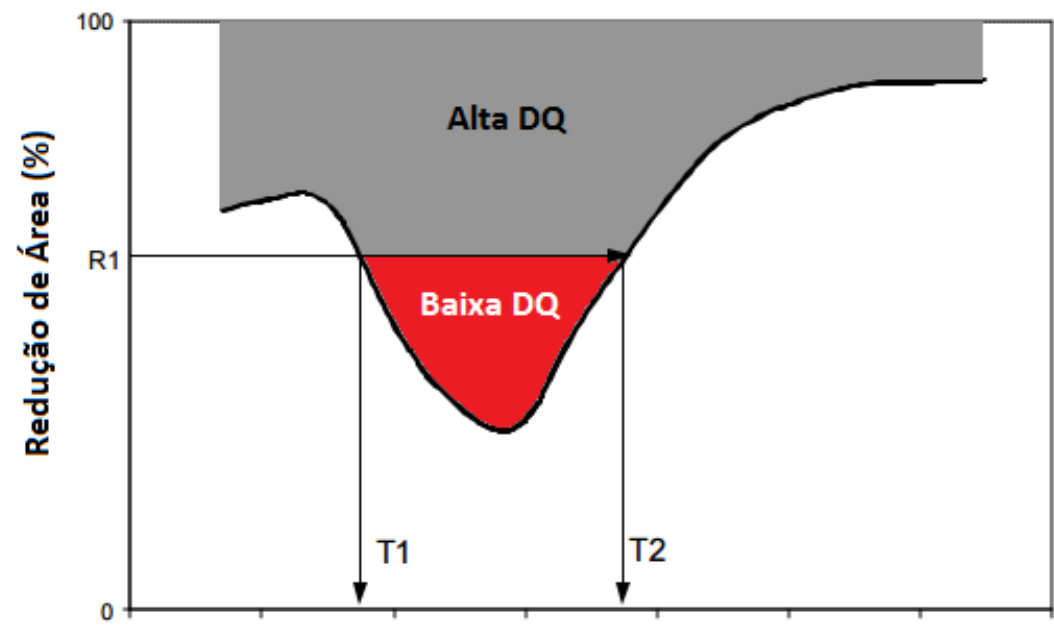

Figura 2 - Desenho Esquemático da região de baixa ductilidade a quente (\%RA<R1) compreendida entre uma faixa de temperatura T1 e T2 (adaptado de 5). 
A seguir serão apresentadas as influências das variáveis de processo na propriedade de ductilidade a quente e o status encontrado dentro da planta siderúrgica analisada.

\subsection{Qualidade de Solidificação do Tarugo}

Estudos relatam que a existência de trincas diagonais está geralmente associada a romboidades pronunciadas e trincas centrais oriundas de tensões mecânicas (rolos extratores) ou térmicas (reaquecimento entre zonas) geradas durante solidificação do aço. Estas trincas podem acarretar em problemas de abertura de cabeça (Perda de ductilidade a quente) durante o processo de laminação [6-8].

A unidade siderúrgica possui uma automação na zona secundária (região dos sprays) baseada em um software desenvolvido internamente para minimizar as tensões térmicas. A Figura 3a ilustra a curva da temperatura da superfície do tarugo durante etapa de solidificação e pode-se observar baixíssimos reaquecimentos entre zonas. A Figura 3b apresenta uma típica macrografia com ausência de trincas e a existência de grãos equiaxiais na região central. Já a Figura 3c apresenta a romboidade do aço utilizado para produção de barras CA-50. Verifica-se $99 \%$ abaixo de $8 \mathrm{~mm}$ - que reforça a excelente capabilidade de processo.

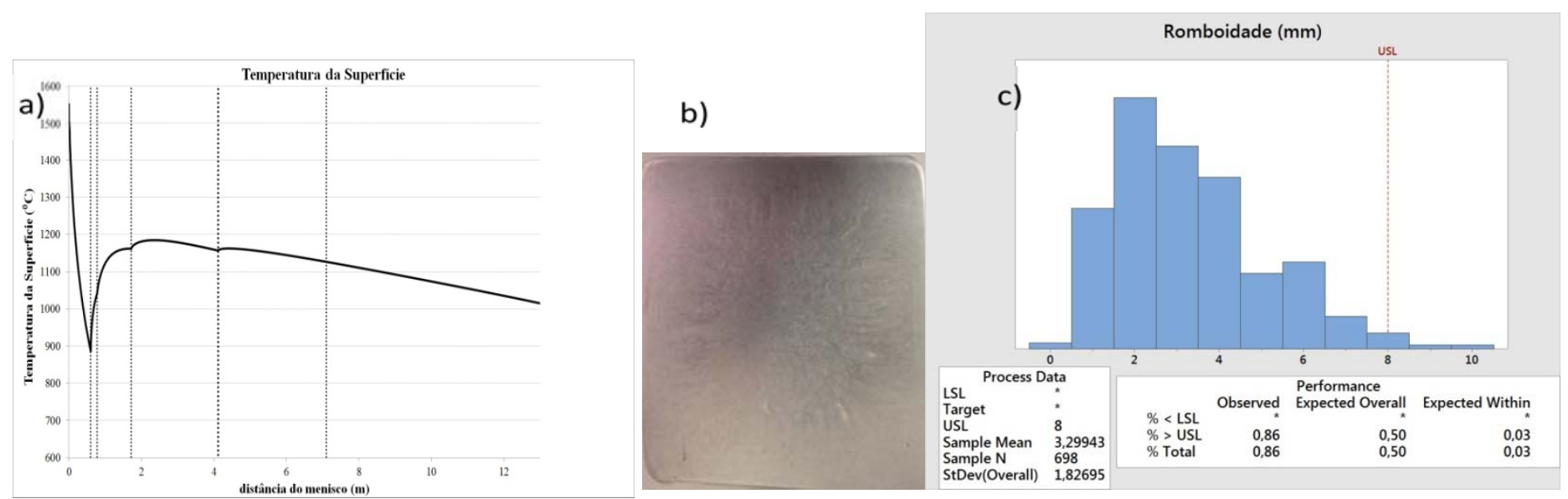

Figura 3 - a) Curva da Temperatura superficial do tarugo durante processo LC, b) Macrografia do tarugo isento de trincas diagonais e centrais com presença de grãos equiaxiais, c) Baixa romboidade do tarugo - média de 3,2 $\mathrm{mm}$ e $99 \%$ abaixo de $8 \mathrm{~mm}$.

\subsection{Tipo de corte do tarugo}

O corte mecânico através de tesoura realiza um esforço severo para promover o cisalhamento da secção transversal do tarugo, afetando a microestrutura da região próxima ao corte conforme exposto na Figura 4a. Este esforço acarreta em uma perda de ductilidade a quente (podendo gerar trincas) quando comparado ao uso do oxicorte (Figura 4b) [9]. A Figura 4c apresenta a secção transversal dos tarugos após processo de oxicorte, e pode-se observar uma boa qualidade da superfície cortada (lisa e regular). 
c)

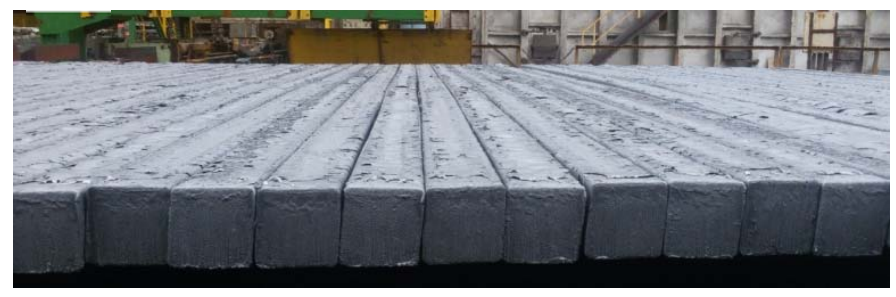

Figura 4 - llustração do corte de tarugos: a) via tesoura apresentando uma região com perda de ductilidade (trincas internas) oriunda do esforço sofrido durante corte e b) via oxicorte, c) Tarugos no

leito de resfriamento após realização do oxicorte. O corte apresenta uma boa qualidade sem existência de sulcos severos na secção.

\subsection{Ciclo térmico}

A literatura apresenta o uso do enfornamento a quente (EQ) como ação de mitigação à redução de distorções ou até mesmo surgimento de trincas devido à existência de uma menor taxa de aquecimento dentro do forno de reaquecimento em detrimento ao enfornamento a frio (EF) [10]. A Figura 5a apresenta as curvas típicas de temperaturas do forno, tarugo enfornado a quente e enfornado a frio.

Tipicamente, ambos os processos de enfornamento ocorrem em temperaturas inferiores a Ac1 (Temperatura da transformação ferrita $\rightarrow$ austenita), tornando favorável o uso de taxas de aquecimento menores, o que promoverá uma maior homogeneidade da temperatura (microestrutura, tamanho de grão) ao longo da seção transversal.

A Figura 5b apresenta o \% de enfornamento a quente $\left(\mathrm{T}>500^{\circ} \mathrm{C}\right)$ praticado nos últimos 12 meses, observa-se que em todos os meses o \% praticado foi superior a $50 \%$.
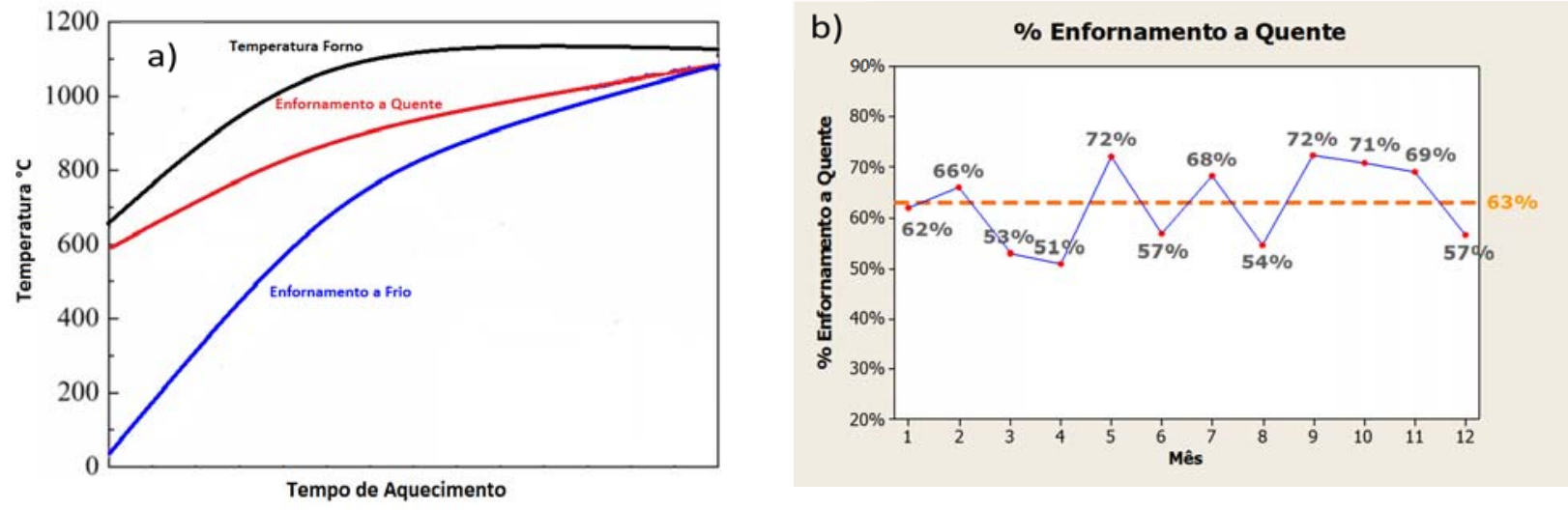

Figura 5 - a) Perfil típico de temperatura do Enfornamento a quente (menor taxa de aquecimento) em relação ao Enfornamento a frio, b) Média de $63 \%$ de Enfornamento a quente da planta siderúrgica o que minimiza a probabilidade de heterogeneidade de temperatura (crítico para abertura de cabeça do laminado).

\subsection{Temperatura de processo de laminação}

O aumento da Temperatura em geral promove maior ductilidade a quente com exceção das zonas de baixa ductilidade (ex. região de transformação de fase) - ver Figura 6a. Usualmente a temperatura encontra-se acima da Tnr (Temperatura de não recristalização da austenita) durante produção de barras de aço CA-50. Para o 
aço utilizado foi obtida pela equação de Boratto uma $\mathrm{Tnr}$ de $925^{\circ} \mathrm{C}$ [11]. Abaixo da Tnr ocorre o encruamento da austenita acarretando em perda de ductilidade a quente. A Figura $\mathbf{6 b}$ apresenta o histograma da Temperatura superficial da barra na entrada da gaiola do $1^{\circ}$ passe do desbaste onde se verifica $100 \%$ dos valores acima da Tnr.

a)

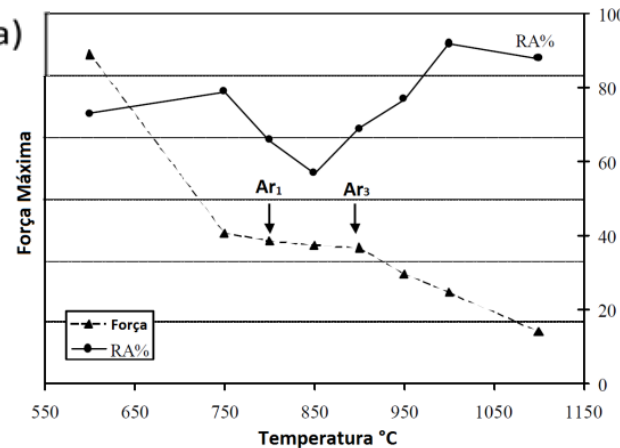

b) Temperatura de entrada do $1^{\circ}$ passe

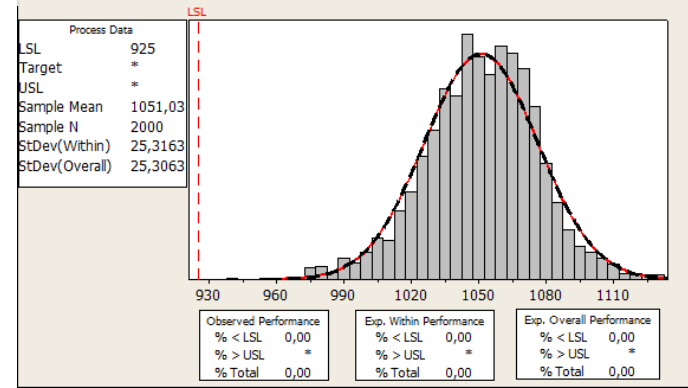

Figura 6 - a) Comportamento típico de ductilidade a quente de aços ao Carbono com perda de ductilidade na região de transformação de fase, b) Temperatura superficial da barra na entrada do $1^{\circ}$ passe de laminação.

\subsection{Tipo do trem de desbaste}

O trem de desbaste aberto (gaiola trio) minimiza a perda de ductilidade da cabeça da barra laminada, uma vez que existe passes contrários ao sentido de laminação que tendem a minimizar uma possível "abertura da cabeça" [Figura 7a]. Já o trem contínuo concentra os impactos da barra sempre na mesma região ocasionando perda de capacidade de deformação [Figura 7b] [12]. A usina siderúrgica analisada possui o trem de desbaste aberto (gaiola trio).

a)

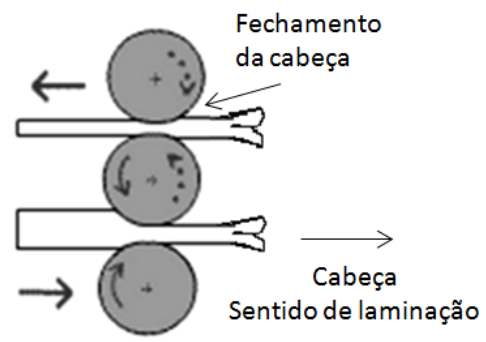

b)

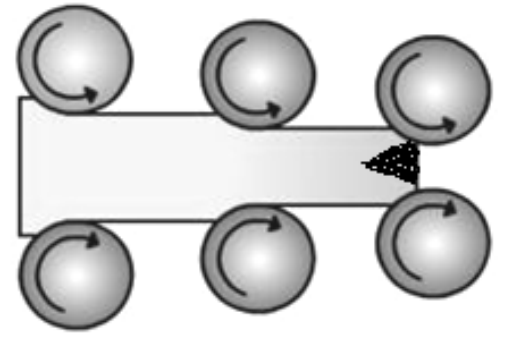

Figura 7 - a) A gaiola trio devido reversão do sentido de passes minimiza a perda de ductilidade, b) $\mathrm{O}$ trem contínuo concentra os esforços na mesma região ocasionando maior perda de ductilidade a quente.

\subsection{Calibração (plano de passes)}

Madias, J. [6] relatou que os planos de passes menos susceptíveis a perda de ductilidade a quente são: box-box, quadrado-redondo e oval-redondo, porém afirmou que a sequência oval-quadrado diferentemente das demais favorece a abertura de cabeça (perda de ductilidade). Essas conclusões foram baseadas na uniformidade das tensões na seção transversal, e na existência de tensões trativas e compressivas. A Figura 8 apresenta a calibração do trem de desbaste atual com a existência de duas sequências de passes "oval-quadrado", sinalizando uma potencial oportunidade no processo. 


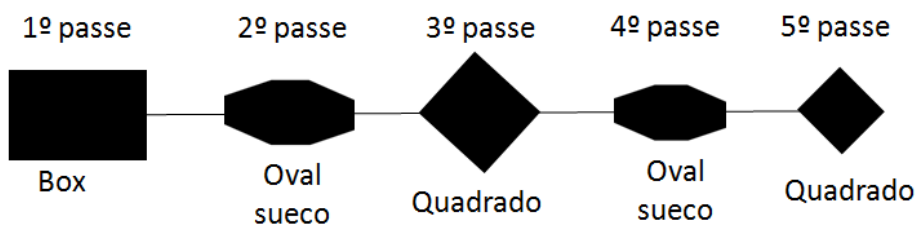

Figura 8 - Sequência de passes do trem de desbaste da calibração para produção de barras de aço CA-50.

\subsection{Taxa de deformação}

A Figura 9a ilustra um critério de perda de ductilidade (abertura de cabeça) durante laminação a quente de aço utilizando o SAE 1020 como referência. O critério indica que a abertura da cabeça tende a ocorrer para pequenos raios de cilindros (Ro), maiores alturas iniciais do passe (ho) e menores reduções $(\varepsilon)$ [8]. A Figura 9 a foi adaptada para apresentar a localização dos 5 primeiros passes do desbaste do processo estudado, onde todos encontram-se dentro da zona de segurança.

Mintz et al. [13] sinalizaram que maiores velocidades de deformação promovem menores perdas de ductilidade a quente em aços Si-Mn (ver Figura 9b). O processo estudado possui elevadas taxas de deformações conforme apresentado na Tabela 1, o que minimiza o risco de perda de ductilidade devido essa variável.

Tabela 1 - Taxa de deformação por passe durante etapa de desbaste.

a)

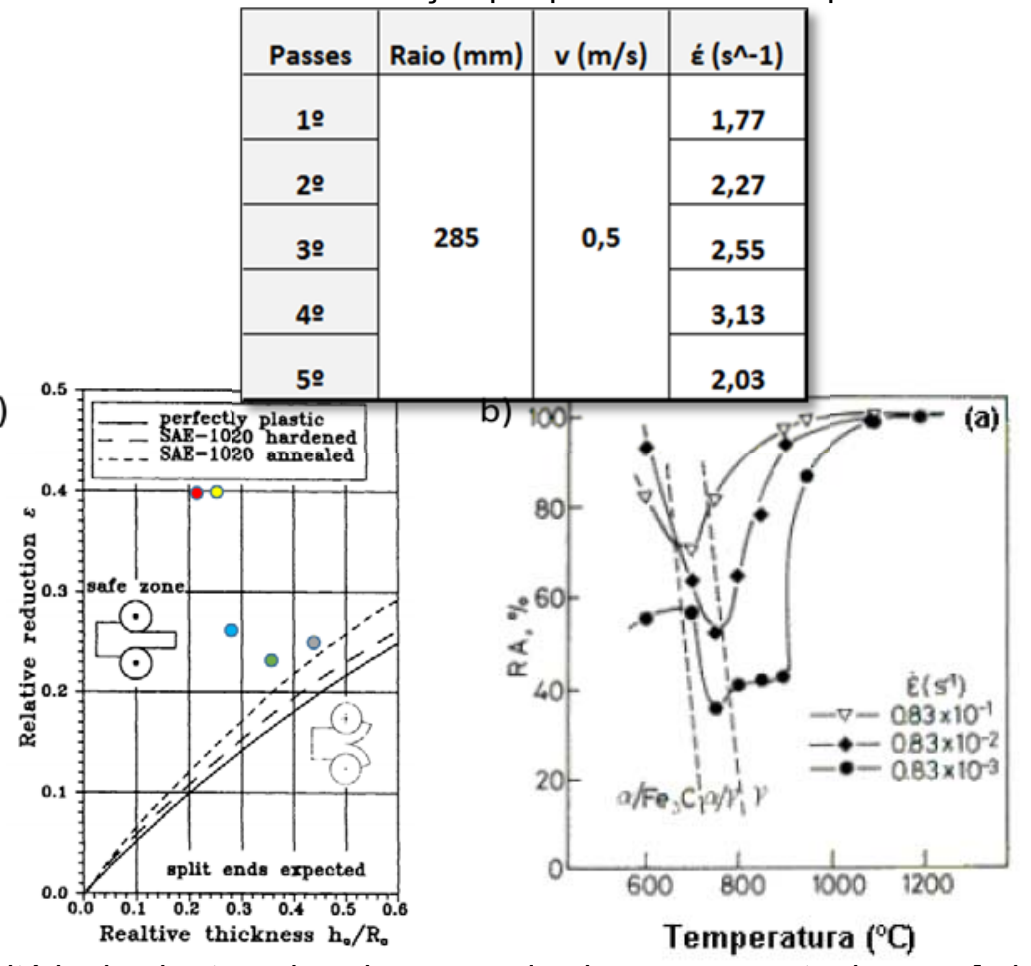

Figura 9- a) Critério de abertura de cabeça para laminação a quente de aços [adaptado de 8], e b) Influência da velocidade de deformação na ductilidade a quente de aços Si-Mn [13].

\subsection{Composição Química}

Os primeiros trabalhos sobre a influência da composição química na ductilidade a quente analisaram basicamente o efeito da relação $\mathrm{Mn} / \mathrm{S}$ e do teor de carbono. A Figura 10a indica claramente que uma maior relação $\mathrm{Mn} / \mathrm{S}$ no aço melhora a sua ductilidade a quente [14]. 
Alguns pesquisadores têm estudado a influência do $S$ e da relação $M n / S$ na susceptibilidade à ocorrência de trinca no lingotamento contínuo de tarugos. Há uma concordância que uma baixa relação $\mathrm{Mn} / \mathrm{S}$ leva à formação de um líquido interdendrítico de FeS de baixo ponto de fusão durante a solidificação. Esta fase irá levar à formação de trinca interna no tarugo durante o lingotamento contínuo ou trinca intergranular durante laminação à quente [15]. Toledo [15] propõe uma relação $\mathrm{Mn} / \mathrm{S}$ crítica, (Mn/S)c, dada pela (Equação 1):

$$
(\mathrm{Mn} / \mathrm{S}) \mathrm{c}=1,345^{*} \mathrm{~S}^{-0,7934}
$$

onde S é o teor de enxofre.

A Figura 10b apresenta que em $100 \%$ das corridas a relação $(\mathrm{Mn} / \mathrm{S}) \mathrm{c}$ foi maior que a relação (Mn/S)aço sinalizando com susceptibilidade a "abertura de cabeça" quando analisado de forma isolada, porém outros parâmetros de processo mitigam esse risco.

Já Visagie [16] fez análise da presença de trincas intergranulares no lingotamento contínuo de tarugos que estariam levando à perda de ductilidade a quente na barra laminada relacionadas ao Cobre, onde a severidade da trinca superficial intergranular estaria relacionada com um valor de "cobre equivalente" (Cueq) expresso pela (Equação 2):

$$
\mathrm{Cu}_{\text {eq }}=\% \mathrm{Cu}+10 \% \mathrm{Sn}-\% \mathrm{Ni}<0,40
$$

A Figura 11a ilustra que aproximadamente metade das corridas produzidas não atendem ao critério proposto por [16]. Melford [17] sinalizou o efeito benéfico do $\mathrm{Ni}$ em minimizar a perda de ductilidade através do incremento da solubilidade do Cu na austenita, reduzindo assim a velocidade de formação de carepa e propiciando o aumento do ponto de fusão da fase rica em cobre presente nos contornos de grão, e propôs uma relação $\mathrm{Ni} / \mathrm{Cu}>0,50$ como forma de minimizar a ocorrência de perda de ductilidade a quente em aços com \%Cu $\sim 0,35$. A Figura 11b apresenta que 97\% dos lotes não atenderam o critério proposto.

Garza-Martínez mostrou que o efeito deletério sobre a ductilidade a quente promovido pelo cobre é altamente dependente da Temperatura de processo conforme exposto na Figura 12 [18]. Portanto, o efeito do cobre sobre a perda de ductilidade a quente não pode ser entendido simplesmente quanto ao \%Cu encontrado no aço, pois é dependente da Temperatura de reaquecimento, taxa de oxidação dentro do forno e dos outros elementos existentes no aço [19]. 

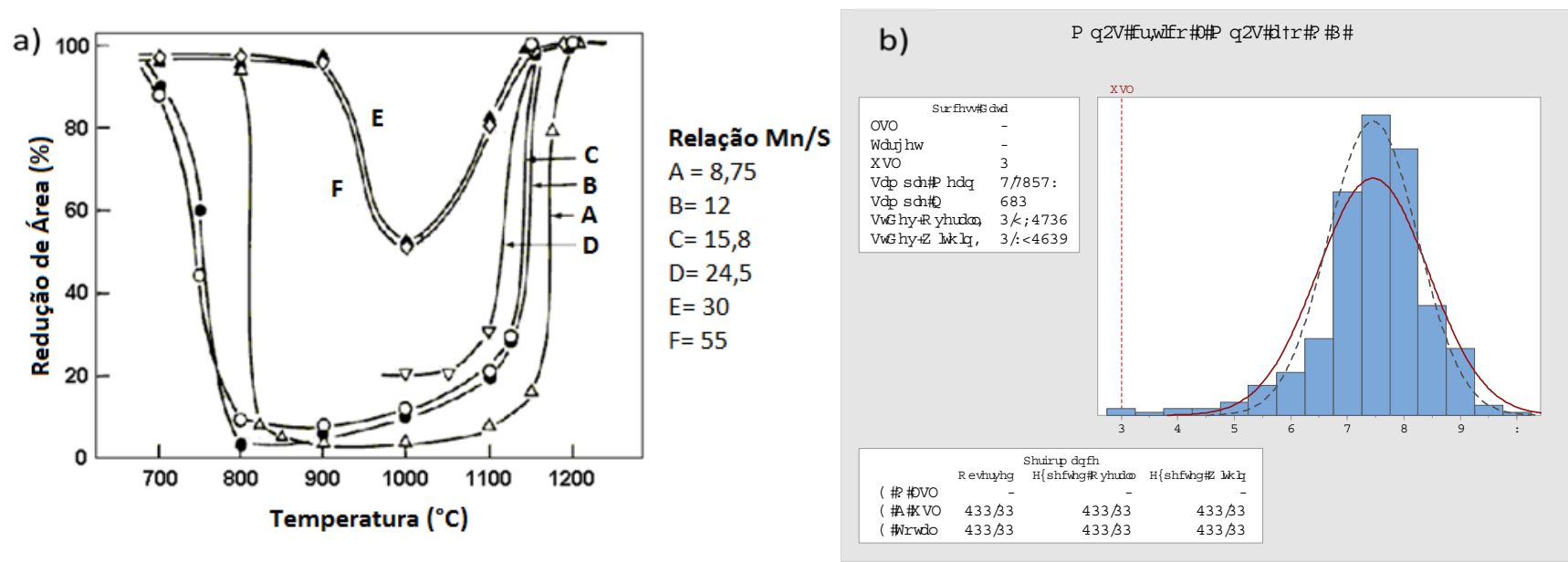

Figura 10 - a) Influência da relação $\mathrm{Mn} / \mathrm{S}$ na ductilidade a quente de aços [14], b) A relação $\mathrm{Mn} / \mathrm{S}$ crítica é superior a relação $\mathrm{Mn} / \mathrm{S}$ aço em $100 \%$ dos lotes produzidos.
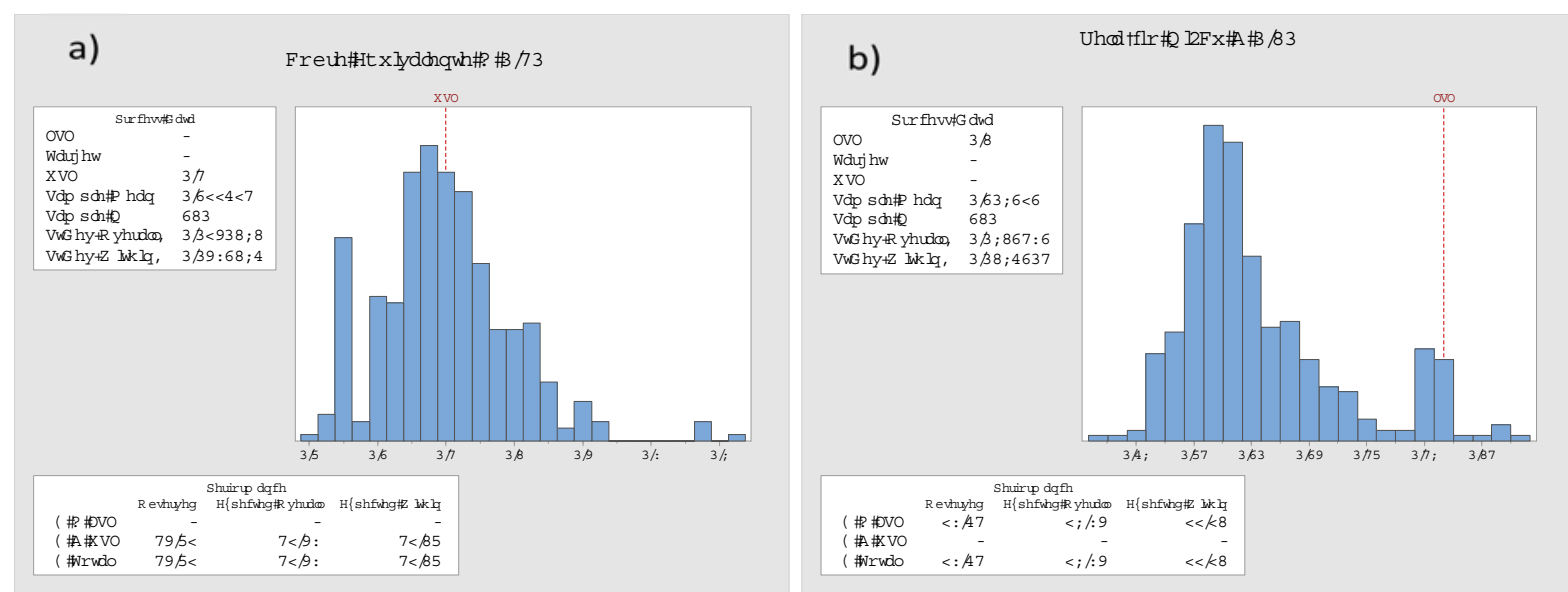

Figura 11 - a) O critério de Cobre equivalente não é atendido em $66 \%$ dos lotes, b) $\mathrm{O}$ critério da relação $\mathrm{Ni} / \mathrm{Cu}>0,50$ não é atendido em $97 \%$ dos lotes.

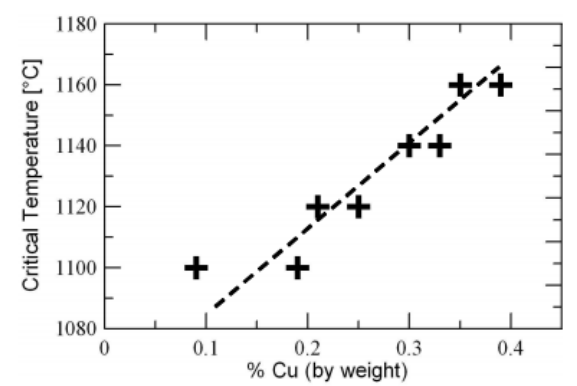

Figura 12 - Temperatura crítica relativa a perda de ductilidade versus \%Cu [18].

Com relação ao \%C, a faixa entre $0,10 \%$ e $0,15 \%$ apresenta maior susceptibilidade à ocorrência de trincas superficiais [20], bem como a região com maiores grãos austeníticos que surgem a partir da reação peritética [21] como exposto nas Figuras 13a e 13b, respectivamente. A Figura 13c apresenta o \%Carbono do aço utilizado para produção de barras CA-50, onde é possível observar o uso da faixa de baixa frequência de trincas superficiais e de tamanhos de grãos austeníticos mais refinados como exposto, o que promove maior resistência mecânica e tenacidade (propriedade extremamente requerida durante os passes de laminação). 

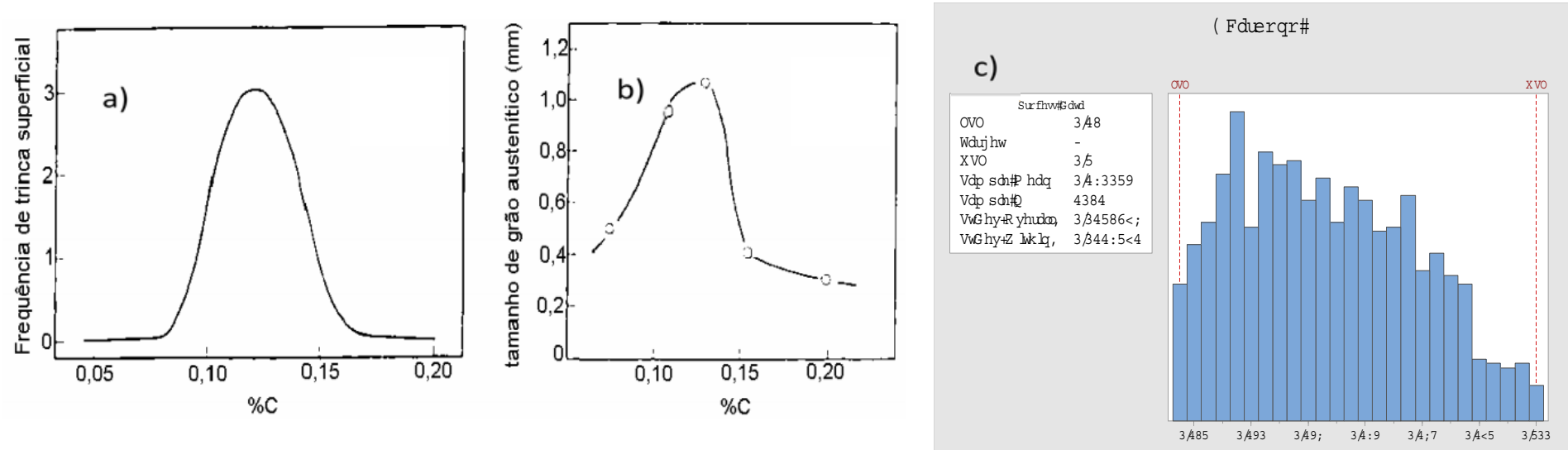

Figura 13 - a) Influência do teor de carbono na ocorrência de trinca superficial [20], b) no tamanho de grão [21], c) \%Carbono do aço utilizado para produção de barras CA-50.

A Tabela 2 sumariza a análise das 10 variáveis de processos analisadas em relação à propriedade de ductilidade a quente. Verifica-se que $70 \%$ das características analisadas atuam de forma a mitigar o risco de perda de ductilidade a quente.

Quanto a calibração do desbaste há um estudo em andamento avaliando a troca da sequência de calibração "oval-quadrado" para "oval-redondo". Já às relações Mn/S e $\mathrm{Ni} / \mathrm{Cu}$, devido não comprometerem a qualidade do produto final, e promoverem um aumento considerável no custo do aço tornam injustificáveis a mitigação do risco através dessas ações.

Tabela 2 - Influência da variável de processo sobre a ductilidade a quente durante laminação de aços ao Carbono: literatura x processo real.

\begin{tabular}{|c|c|c|c|}
\hline & Pontos favoravéis a Ductilidade a quente & \multirow[b]{2}{*}{ Processo Real } & \multirow[b]{2}{*}{ Status do Case } \\
\hline & \begin{tabular}{|c|} 
Literatura \\
\end{tabular} & & \\
\hline Qualidade da solidificação do tarugo & Isenção de trincas diagonais e centrais & Ok conforme literatura & + \\
\hline Tipo de corte do tarugo & oxicorte & Ok conforme literatura & + \\
\hline Ciclo térmico & enfornamento a quente & Ok conforme literatura & + \\
\hline Temperatura de processo de laminação & Tlam $>$ Tnr & Ok conforme literatura & + \\
\hline Tipo do trem de desbaste & Gaiola trio & Ok conforme literatura & + \\
\hline Calibração do desbaste & exceto Oval - Quadrado & não atendido & - \\
\hline Taxa de deformação & $>10^{-2} \mathrm{~s}^{-1}$ & Ok conforme literatura & + \\
\hline$M n / S$ & $\mathrm{Mn} / \mathrm{S}$ aço $>\mathrm{Mn} / \mathrm{S}$ crítico & não atendido & - \\
\hline $\mathrm{Ni} / \mathrm{Cu}$ e $\mathrm{Cu}$ equivalente & $\mathrm{Ni} / \mathrm{Cu}>0,50$ \& $\mathrm{Cu}$ eq $<0,40$ & não atendido & - \\
\hline$\% \mathrm{C}$ do aço & $0,15<\% \mathrm{C}<0,19$ & Ok conforme literatura & + \\
\hline & & TOTAL & $70 \%+$ \\
\hline
\end{tabular}

\section{CONCLUSÃO}

1 As condições favoráveis de processo - qualidade da solidificação, tipo de corte, ciclo térmico, temperatura de processo, layout do laminador, taxa de deformação e \%C no aço - sobre a ductilidade a quente permitiram uma solução otimizada de menor custo.

2 Através da ferramenta ALARP (custo-benefício) foi possível criar uma estratégia mais ousada dentro do processo priorizando o menor custo de aço em detrimento a outros "trade-offs" (Ex: confiabilidade e disponibilidade máxima do Laminador). 
3 A metodologia ALARP permite dentro de uma analise de riscos, avaliar condições de processo e adotar estratégias que por sua vez, fogem dos conceitos e práticas consolidadas.

4 Cada vez mais, em um cenário onde as conjunturas globais nos remetem a atitudes cada vez mais ousadas, o uso de ferramentas desta natureza torna-se importante para garantir a competitividade e sustentabilidade do negócio.

5 O não atendimento as relações tradicionais de $\mathrm{Mn} / \mathrm{S}$ e Ni/Cu foram mitigados por outros parâmetros, uma vez que implica em ligas de elevado custo (Ni e Mn).

6 A análise holística sobre os parâmetros de processo influentes na ductilidade a quente mostrou-se atrativa perante a estratégia de menor custo do aço, garantindo as especificações técnicas do produto e a sua aplicação final.

\section{REFERÊNCIAS}

1 Soares, C. G.; Teixeira, A. P., Critérios Económicos e Sociais de Aceitabilidade de Risco. In P. Antão, Riscos Públicos e Industriais (pp. 45 - 64). Lisboa: Edições Salamandra, 2007.

2 Rowley, I., Managing in an Uncertain World: Risk Analysis and The Bottom Line. IEE Colloquium: Systems Engineering Contribution to Increased Profitability, 1989.

3 Ferreira, F.H.I., Gestão do Risco Industrial numa Central Termoeléctrica de Ciclo Combinado, IST - Universidade Técnica de Lisboa, Dissertação de Mestrado, 2008.

4 AS/NZS 4360:2004. Risk Management Guidelines - Companion to AS/NZS 4360:2004. Standards Australia/Standards New Zealand.

5 Ruddle, G.E., Effects of Residuals in Carbon Steels, AISI, Technology Roadmap Program, 2002.

6 Madias, J., Split Ends During Long Products Rolling: Billet Quality or Rolling Process?, Conference: AISTech 2014 Conference Proceedings pp. 2591-2602

7 Pandey, J.C., Raj, M., Choubey, P.N., Split Ends and Cracking Problem During Hot Rolling of Continuously Cast Steel Billets, J. Fail. Anal. And Preven. 9; 88-96, 2009.

8 Malinowski, Z.; Turczyn,, S.; Split ends and central burst defects in rolling, Materials Processing Defects, S.K. Ghosh and M. Predeleanu (Editors), 1995.

9 Ramalho, J.P., Oxicorte: Estudo da transferência de calor e modelamento por redes neurais artificiais de variáveis do processo, Tese de Doutorado, Escola Politécnica da Universidade de São Paulo, 2008.

10 Totten, G.E., Howes, M.A.H., Steel Heat Treatment Handbook, Marcel Dekker, 1997

11 Boratto, F. e outros. In: THERMEC '88. Proceedings. ISIJ, Tokyo, 1988, p. 383-390.

12 IIR Board of Consultants \& Engineers, The Complete Technology Book On Hot Rolling Of Steel, 656p, 2010.

13 Mintz, B.; Yue, S.; Jonas, J. J. Hot ductility of steels and its relationship to the problem of transverse cracking during continuous casting. International Materials Reviews, v. 36, n. 5, p.187-217, 1991.

14 Maehara, Y.; Nakai, K.; Yasumoto, K.; Mishima, T. Transactions Iron Steel Institute, p. $1021,1988$.

15 Toledo, G.A.; Campo, O. \& Lainez, E. "Influence of sulfur and Mn/S ratio on the hot ductility os steels during continuous casting". Process Metallurgy, 1992.

16 Visagie, G.P. \& Van Wijngaarden, M.J.U.T. "The effect of residuals on the presence of intergranular surface cracks on continuously cast billets". Steelmaking Conference Proceedings, p. 627-631, 1996.

17 Melford, D.A., Surface Hot Shortness in Mild Steel, JISI, April, 1962.

18 Garza-Martínez, L.G. Workability of 1045 forging steel with residual copper, Ed. Colorado School of Mines, 103p., 2003

19 European Commission, Effects of tramp elements in flat and long products, Final Report, 1995. 
20 Revaux, T.; Deprez, P.; Bricout, J. P.; Oudin, J. In-situ solidified hot tensile test and hot ductility of some plain carbon steels and microalloyed steels, ISIJ Int., v. 34, n.. 6, p. 528-535, 1994.

21 Wolf, M. M. Estimation method of crack susceptibility for new steel grades. European Conference on Continuous Casting, Florence, Italy, 1991. p. 2489-2499. 